\title{
LA ARQUEOLOGÍA DEL CONFLICTO EN EL PAÍS VASCO Y SU POTENCIAL DIDÁCTICO
}

\author{
Aritza Sáenz del Castillo Velasco ${ }^{1}$
}

\section{Resumen:}

Tradicionalmente en el mundo educativo la ciencia arqueológica ha estado relacionada con el estudio de tiempos lejanos como la Prehistoria, la Edad Antigua y ocasionalmente la Edad Media. La presente comunicación analiza el potencial didáctico que ofrece la arqueología del conflicto para la comprensión y el aprendizaje de determinados periodos de la historia, y muy especialmente la contemporánea. Así, el abundante patrimonio material y arqueológico generado por la guerra civil española que discurrió de 1936 a 1939 se transforma en un recurso importante y novedoso para la enseñanza-aprendizaje de la historia de este periodo concreto, que trasciende la visión positivista y poco motivadora de los libros de texto y su metodología expositiva. En esta línea, mediante el empleo de las TIC (Tecnologías de la Información y Comunicación) y concretamente la página web que contiene El Mapa de Fosas del País Vasco y su aplicación informática, nos permitirá traer a las aulas una multitud de casos y espacios relacionados con la arqueología del conflicto, que ayudarán al alumno a interactuar con el medio de una forma virtual y autónoma y a comprender mejor este periodo de nuestra historia reciente en aspectos tan fundamentales y que requieren de una reflexión pausada, como pueden ser la divergencia de pareceres y su tratamiento y la resolución de conflictos por medio de la violencia y sus dramáticas consecuencias.

\section{Palabras clave:}

Arqueología del Conflicto, Guerra civil española de 1936, País Vasco, Didáctica de la Historia, Mapa de Fosas.

\section{Abstract:}

In education, archeology science usually has been related to the study of Prehistory, Ancient Times and the Middle Age. This paper will analyze the didactic power of Conflict Archeology to understand and learn some periods of history, especially Contemporary once. The huge heritage of the Spanish Civil War dated between 1936 and 1939 is a new and important resource for teaching-learning the history of this period, beyond the positivist view of the text-books and the speech methodology. In this way, the use of Information and Communication Technologies, and especially El Mapa de Fosas del País Vasco web site, allows us to carry to school classes a lot of examples related to Conflict Archeology which help the students to understand better this period of our history. Furthermore, this resource

1 Profesor Laboral Interino del Departamento de Didáctica de las Ciencias Sociales aritzasaenz80@hotmail.com 
goes in depth in the reflection about the dramatic effects of the war and how the human been can sort out his problems in other way.

\section{Key words:}

Conflict Archeology, Spanish Civil War 1936-1939, Basque Country, Teaching-Learning history, Grave's map

\section{Introducción}

La guerra civil española de 1936 y el franquismo son dos periodos de la historia que han suscitado acalorados debates sociopolíticos e intelectuales en los últimos años. Así se han puesto en marcha numerosas iniciativas sociales -asociaciones por la recuperación de la memoria histórica, el Foro por la Memoria, la localización y exhumación de fosas comunes, la reparación de las víctimas de guerra civil y el franquismo-, culturales -filmografía, literatura...- y académicas que han tenido como objetivo la indagación, el estudio y la difusión de ciertos hechos o acontecimientos acaecidos en esta etapa reciente de nuestra historia y que culminaron con la rúbrica de la conocida comúnmente como Ley de Memoria Histórica en 2007 y una amplia bibliografía al respecto ${ }^{2}$. Esta repercusión social ha tenido su eco en el mundo educativo. Así, en fechas recientes la enseñanza-aprendizaje de la historia de la guerra civil española y el franquismo han sido analizadas profusamente desde el área de la didáctica de las Ciencias Sociales. Fruto de esta labor, han tenido lugar numerosos congresos y han visto la luz varias publicaciones que han puesto el foco de atención entre otros aspectos en la actividad docente y en el tratamiento de los contenidos a enseñar-aprender; en la carga ideológica de los éstos; en la formulación de propuestas didácticas novedosas y las aportaciones al conocimiento histórico resultantes del empleo de nuevos recursos didácticos, etc. Siendo un tema de actualidad social y sumándonos a los estudios realizados, creemos que es importante analizar su tratamiento en el aula y reparar en su proceso de enseñanza-aprendizaje ${ }^{3}$.

2 Como ejemplo el monográfico de la revista Hispano Nova de 2006 titulado "Generaciones y memoria de la represión franquista: un balance de los movimientos por la memoria", o los siguientes artículos: J.A. BLANCO RODRÍGUEZ: "La historiografía de la guerra civil española". Hispano Nova, 7 (2007); F. FERRÁNDIZ MARTíN: "Exhumaciones y políticas de la memoria en la España contemporánea". Hispano Nova, 7 (2007).

3 La reciente obra de M. TORRUELLA y F.X. HERNÁNDEZ CARDONA: Didáctica de la Guerra Civil española. Graó, Barcelona: 2013 ofrece un estado de la cuestión del tratamiento político, social, historiográfico y educativo sobre la guerra civil de 1936 y plantea numerosas propuestas didácticas desde varios enfoques y metodologías novedosas e interactivas. Reflejo del interés que suscita en la comunidad educativa destacaría el Congreso Internacional celebrado en la Universidad Complutense de Madrid en abril de 2014 bajo el título "Posguerras: 75 aniversario del fin de la Guerra Civil española", que dedicó una sesión completa a su didáctica. 
La didáctica de la guerra civil hoy en día sigue influenciada en gran medida por la historia positivista y eminentemente política; por lo tanto, centra su atención en los grandes personajes de la historia, su devenir y en el comportamiento de las diferentes agrupaciones políticas y sindicales, como reflejo de la evolución que experimenta la sociedad en este periodo de la historia de España. Es una historia básicamente descriptiva, donde el análisis e interpretación brillan por su ausencia. De este modo, los contenidos más relevantes a estudiar suelen ser: la evolución política del bando republicano y del nacional-golpista, las zonas que quedaron bajo influencia de cada bando, la descripción de los frentes de batalla y su evolución, la organización de ambos ejércitos, la repercusión e intervención internacional y las consecuencias de la guerra. A pesar de ello, en los últimos años han ido introduciéndose contenidos propios de las nuevas corrientes historiográficas, y así aspectos como la economía, la cultura, etc. han adquirido relevancia. Aun así, siguen alejados de una historia social y de la vida cotidiana que sí que ha irrumpido en la esfera académica.

Por otra parte, la enseñanza y aprendizaje de la guerra civil española de 1936 y de la historia en general, ha discurrido dentro de los cauces magistrocentristas o expositivos, donde el profesor contribuía a la difusión de los contenidos y estos eran asimilados por los estudiantes mediante el empleo de manuales de historia, bajo un ambiente cargado de monotonía ${ }^{4}$. La historia era concebida como una asignatura teórica sin posibilidad de poder enseñarse y aprenderse a través de clases prácticas, donde el docente era un mero transmisor de conocimientos que debía doblegarse a "las cadenas del imperio de la teoría" ${ }^{5}$. El distanciamiento del profesorado respecto a las prácticas investigadoras era más que evidente. La historia era una disciplina acabada con unos contenidos que no se cuestionaban y poco o nada se reparaba en su proceso de creación del conocimiento científico. Aun así, a partir de la Ley General de Educación de 1970 y la instauración del Bachillerato Unificado Polivalente 5 años más tarde, se produjo una renovación pedagógica y didáctica. Los libros de texto fueron incorporando fuentes históricas primarias dentro de sus unidades didácticas al objeto de desarrollar en el alumnado la capacidad de análisis y trabajar su comprensión e interpretación y a la vez mejorar sus capacidades cognitivas. Esta tendencia fue renovada y ampliada en 1992 con la reforma del bachillerato LOGSE, donde los contenidos procedimentales adquirieron gran importancia y la metodología de la ciencia histórica -aprendizaje por indagación- centró buena parte de los ejercicios de los manuales de historia. Lamentablemente

4 El poema "Recuerdo Infantil" de Antonio Machado recoge a la perfección esta atmosfera poco motivadora para el aprendizaje "...Los colegiales estudian. Monotonía de la lluvia en los cristales. Es la clase (...) y todo un coro infantil va cantando la lección: mil veces ciento, cien mil; mil veces mil, un millón..." en A. MACHADO: Soledades. Galerías. Otros poemas. s.l., s.n.: 1907.

5 J.A. ÁLVAREZ OSÉS et al.: La guerra que aprendieron los españoles. República y guerra civil en los textos de bachillerato (1938-1983). Libros de la Catarata, Madrid: 2000, p. 76. 
este proceder fue arrinconado con la reforma educativa de 2001 y la vuelta a la historia general y enciclopedista ${ }^{6}$.

\section{Aportaciones didácticas de la arqueología del conflicto}

La arqueología tradicionalmente ha sido una ciencia vinculada a la investigación de tiempos remotos. No obstante a partir de la segunda mitad del siglo XX aparecieron nuevas corrientes dentro de esta disciplina que centraron su estudio en la contemporaneidad ${ }^{7}$. Así, el desarrollo y la evolución de los núcleos urbanos habitados y por consiguiente vivos y activos, y el interés sobre la conservación del patrimonio histórico-arqueológico de las ciudades ante los avatares de la guerra, la reurbanización de los centros históricos, etc. impulsó la aparición de la arqueología urbana, con sus métodos de análisis y documentación propios ${ }^{8}$. De igual modo, el interés por el patrimonio industrial germinó en una nueva disciplina, la arqueología industrial ${ }^{9}$. En esta línea, la arqueología del conflicto es una disciplina reciente que surgió a raíz del deterioro del patrimonio vinculado a acontecimientos bélicos y con la clara intención de analizar, interpretar y documentar la información histórica-antropológica y las trazas materiales presentes en estos lugares y contribuir al conocimiento exhaustivo de estos acontecimientos históricos y al mismo tiempo a la conservación y preservación de estos espacios patrimoniales ${ }^{10}$.

Pese a estos avances en la ciencia arqueológica, el sistema educativo todavía adolece de cierto retraso y no se ha adaptado a estas nuevas corrientes. Así, los

6 R. VALLS MONTES: Historia y memoria escolar. Segunda República, Guerra Civil y dictadura franquista en las aulas. Publicacions de la Universitat de Valencia, Valencia: 2009, p. 113. Para una visión fundamentada, crítica e integradora ante la dicotomía escuela tradicional-expositiva y la escuela innovadora-activa A. ZABALA y L. ARNAU: 11 ideas clave. Cómo aprender y enseñar competencias. Graó, Barcelona: 2007, pp. 53-63.

7 V. BUCHELI y G. LUCAS: Archaeologies of the Contemporary Past. Routledge, Londres:2001

8 Una reflexión interesante sobre la arqueología urbana en el País Vasco se recomienda A. AZCARATE y I. GARCÍA: "La ciudad, documento histórico: reflexiones sobre la práctica de la arqueología urbana en la comunidad Autónoma del País Vasco". KOBIE (serie paleoantropología), 23 (1996), pp. 141-161.

9 Un análisis pormenorizado sobre las investigaciones y publicaciones sobre arqueología industrial en O. VERGARA: "Arqueología Industrial. Un comentario bibliográfico tras medio siglo de historiografía". AnMurcia, 25-26 (2009-2010), pp. 275-300.

10 Para un análisis de su génesis y el actual estado de la cuestión en Europa se recomienda J. SCHOFIELD, W. G. JOHNSON y C. M. BECH (eds.): Matériel Culture. The Archaeology of twentieth century conflict. Routledge, Londres: 2002; J. PRICE: "Orphan Heritage: issues in Managing the Heritage of the Great War in Northern France and Belgium". Journal of Conflict Archaeology, 1 (1) (2005), pp. 181-196; A.T. MYERS: "Between Memory and Materiality: an Archaeological Approach to Studying the Nazi Concentration Camps". Journal of Conflict Archaeology, 4 (1-2) (2008), pp. 231-245. N.J. SAUNDERS: "Excavating Memories: Archaeology and the Great War, 1914-2001". Antiquity, 76 (291) (2002), pp. 101-108. 
contenidos relacionados con la arqueología presentes en el currículum no se han renovado y la transposición del conocimiento histórico-arqueológico continúa estrechamente relacionada con la Prehistoria o la Edad Antigua y decrece a medida que nos acercamos al presente. En este sentido, la arqueología del conflicto y su tratamiento del patrimonio se transformará en un recurso didáctico que puede aportar nuevas estrategias y procedimientos didácticos en la enseñanza-aprendizaje de la historia contemporánea, y más concretamente de la guerra civil española, en cuanto a su impulso de propuestas didácticas más activas y participativas, considerando importante el empleo de fuentes primarias para la construcción del conocimiento histórico en favor de una mayor capacitación cognitiva del alumno (analizar, interpretar) ${ }^{11}$. Así, a través de estos aprendizajes basados en experiencias directas, aparte de profundizar en los contenidos conceptuales, también adquirirán una importancia destacada los procedimentales relacionados con la recogida y el tratamiento de la información, claves del aprendizaje por descubrimiento ${ }^{12}$. Además, esta disciplina nos acercará a aspectos históricos de la vida cotidiana que la historia narrativa positivista de los libros de texto y los análisis documentales dejan de lado -el día a día del combatiente, los avatares de la población civil ante los bombardeos, la vestimenta utilizada, la alimentación, etc.-, lo que le aportará un valor didáctico importante, como resultado de la construcción de un conocimiento profundamente significativo debido al carácter próximo y vivencial que concede al enfrentamiento armado. A su vez, el análisis y la interpretación de los escenarios del conflicto y de los protagonistas de los hechos históricos allí producidos generarán en el discente emociones, valores y posicionamientos de empatía que redoblarán su motivación ante el proceso de aprendizaje.

Los espacios patrimoniales objeto de estudio de la arqueología del conflicto son muy variados. Así los campos de batalla, las trincheras, las fortificaciones o los espacios poliorcéticos, las zonas bombardeadas, los centros de detención y los campos de concentración, las fábricas de armamento, los polvorines, los campos de aviación, las fosas de enterramiento, y un largo etc. componen las áreas a investigar y de las cuales se extraerá conocimiento histórico. La guerra civil española, debido a su duración y su enorme implicación y repercusión sobre la población civil, fue pródiga en la creación de estos espacios patrimoniales, y por lo tanto un periodo histórico al que se puede aportar gran conocimiento si se parte de investigaciones provenientes de la arqueología del conflicto ${ }^{13}$. Es hora que

11 Sobre las implicaciones didácticas de la arqueología de la guerra civil española M. TORRUELLA y F.X. HERNÁNDEZ CARDONA: Didáctica de la Guerra Civil española..., ob. cit. pp. 75-84 o el monográfico de la revista Íber Didáctica de las Ciencias Sociales, Geografía e Historia, 73, 2013.

12 M. GRAS: "Modelos teóricos en el aprendizaje II" en A. AGUIRRE y J.M ÁLVAREZ: "Psicología de la educación". PPU, Barcelona: 1987, pp. 135-162.

13 Sobre el estado de la cuestión de la arqueología de la guerra civil se recomienda los artículos de J. MONTERO GUTIÉRREZ: "La visibilidad arqueológica de un conflicto inconcluso: la exhumación de fosas comunes de la Guerra Civil española a debate". Munibe (Antropología-Arkeología), 
estos lugares tengan el reconocimiento que merecen por parte de la comunidad científica-educativa y se destierren las frecuentes prácticas furtivas y fetichistas de coleccionistas y aficionados de la historia a ellos asociados que en nada ayudan en la construcción del conocimiento ${ }^{14}$.

Los espacios del conflicto y su materialidad contribuyen a su vez a transformar el entorno patrimonial próximo en un recurso didáctico importante debido a su capacidad de generar percepciones sensoriales directas en el alumno, facilitando su interacción con el medio de forma eficaz. De este modo, la didáctica basada en la arqueología del conflicto se suma a una larga tradición pedagógica que sitúa al alumno en el centro del proceso de aprendizaje y que tiene sus máximos exponentes en Decroly, Dewey y Freinet. Por su parte, la didáctica de la arqueología del conflicto también contribuye al desarrollo curricular constructivista en la medida que el aprendizaje de los conceptos es asociado a la utilización de una serie de informaciones relativas a hechos y situaciones reales del entorno natural, social y cultural del alumno pero sin perder la perspectiva global, en pos de un aprendizaje significativo y funcional. Por último, el estudio de estos espacios patrimoniales relacionados con la arqueología del conflicto, puede transcender los propios fines u objetivos de las Ciencias Sociales e internarse en la enseñanza-aprendizaje de otras áreas de conocimiento, como pueden ser las Ciencias Naturales, contribuyendo a la enseñanza integral y a la interdisciplinariedad, pues su entorno proporciona abundante información sobre aspectos meteorológicos, climáticos, faunísticos, de vegetación, biológicos, etc ${ }^{15}$.

Dicho lo cual, en la presente comunicación vamos a analizar un potencial recurso didáctico de la arqueología del conflicto basado en las TIC (Tecnologías de la Información y de la Comunicación), como es el mapa de fosas de Euskadi. El estudio a través de este recurso didáctico interactivo de los proyectos de prospección y excavaciones arqueológicas en espacios patrimoniales relacionados con la Guerra Civil española, y más exactamente, con la represión ejercida por los sublevados en el País Vasco, contribuye al acercamiento al pasado desde los

60 (2009), pp. 289-308; P. ALONSO GONZÁLEZ: "Reflexiones en torno a una Arqueología de la Guerra Civil: el caso de Laciana (León, España)". Munibe (Antropología-Arkeología), 59 (2008), pp. 291-312; A. GONZÁLEZ RUIBAL: "Arqueología de la Guerra Civil Española". Complutum, 19 (2008), pp.11-20; o la comunicación de G. CARDONA GÓMEZ et al., "Didáctica del Patrimonio de la Guerra Civil española: balance y nuevas perspectivas desde DIDPATRI", en Congreso Internacional Posguerras. 75 aniversario del fin de la Guerra Civil española, 3-5 de abril de 2014. Fruto de esta labor científica y de la importancia que va adquiriendo esta disciplina dentro del saber arqueológico es la celebración del I Congreso Internacional de Arqueología de la Guerra Civil Española, los días del 9 al 13 de diciembre de 2014 en Vitoria-Gasteiz.

14 F.X. HERNÁNDEZ CARDONA y X. RUBIO: "Arqueología, conflicto y didáctica. El Born, siglo XVIII". Íber, Didáctica de las Ciencias Sociales, Geografía e Historia, 73 (2013), pp. 35-42.

15 A.L. GARCíA RUIZ (coord.): Didáctica de las Ciencias Sociales, Geografía e Historia en la Enseñanza Secundaria. Grupo Editorial Universitario, Granada: 1997, pp. 239-242. 
lugares donde pervive materialmente la memoria y nos ayudará a profundizar en el conocimiento de este periodo y sus dramáticas consecuencias. Consideramos adecuado el uso de esta TIC, pues con ello posibilitaremos que el alumno desarrolle sus capacidades para interactuar en la actual sociedad de la información y esté a la altura de las nuevas demandas comunicativas. Igualmente, este recurso didáctico aporta inmediatez en la información y facilita el estudio de variedad de casos a través de la indagación activa del alumno, contribuyendo a la construcción autónoma del conocimiento.

El uso de esta herramienta TIC como actividad de aprendizaje formará parte de la programación del aula de $4^{\circ}$ de la E.S.O. Debe ser la actividad que cierre la unidad didáctica sobre el conflicto armado que asoló España de 1936 a 1939 y corresponderá a la fase de aplicación, ampliación y refuerzo de los contenidos adquiridos, pues su empleo para que resulte eficaz requiere de conocimientos previos sobre la materia -el desarrollo de la guerra civil en Euskadi y el frente norte-. Nos ayudará a trabajar el $3^{\circ}$ bloque de contenidos presente en el actual currículum oficial de la Comunidad Autónoma Vasca referido a los "Grandes Conflictos del siglo XX", donde el tratamiento de la guerra civil en Euskadi tiene un apartado propio y resulta vital para la comprensión de los orígenes de muchos de los debates que sacuden la sociedad actual. En este sentido, la guerra civil hay que entenderla como parte de un proceso que tuvo repercusiones en el mundo entero y donde entraron en conflicto los intereses de diferentes grupos sociales y su cosmovisión sobre la organización social.

El encaminar el proceso de aprendizaje a través de este recurso didáctico basado en la arqueología del conflicto nos ayudará a perseverar en los objetivos generales marcados para esta etapa de educación secundaria, ya que el alumno se aproximará de una forma activa al conocimiento de su pasado más reciente adquiriendo las primeras nociones sobre la investigación histórica y siendo capaz de reflexionar críticamente y realizar sus propias interpretaciones sobre los hechos históricos y la evolución de la sociedad que le rodea. De este modo, establecerá una dialéctica entre lo local y lo global, apercibiendo que la historia, más allá de los grandes escenarios bélicos y los estadistas de renombre presentes en los libros de texto, discurre en su entorno próximo, es decir, en su espacio vivencial, y es protagonizada por personas cercanas a él. En segundo lugar, el estudio de la historia mediante el uso esta herramienta TIC pondrá en valor parte del patrimonio cultural e histórico del País Vasco y potenciará hacia él actitudes de respeto y conservación, ya que estos comportamientos son realmente alcanzables cuando se entiende y se comprende el patrimonio. Por último, el empleo de esta TIC contribuirá al desarrollo competencial óptimo del alumno, pues a través de un proceso de aprendizaje semiautónomo y semi-estructurado, aprenderá a aprender estableciendo su propias estrategias de aprendizaje; se encaminará hacia su capacitación en cuanto al tratamiento de 
la información (búsqueda, acceso, selección, organización, contraste, interpretación, síntesis) y el uso de las tecnologías digitales, profundizando en esta particular alfabetización y en la competencia científica; trabajará la competencia social y ciudadana a través de la generación de empatía y el reforzamiento de los valores democráticos y el respeto por los derechos humanos, derivados de la recuperación de la memoria y el reconocimiento moral y social de aquellos ciudadanos y ciudadanas que defendieron la libertad por encima de todo, incluida sus vidas; y finalmente, y no pretendiendo ser exhaustivo, adquirirá destrezas en la competencia lingüística y de comunicación al tener que elaborar sus conocimientos a través de la lectura y transmitirlos tanto de forma oral como escrita (exposición coherente y fundamentada de ideas, convicciones, opiniones, sentimientos y experiencias, etc.).

\section{El mapa de fosas de euskadi}

El mapa de fosas de Euskadi se encuentra dentro de un proyecto más amplio impulsado por la Secretaria General para la Paz y la Convivencia del Gobierno Vasco en colaboración con otras entidades del mundo científico y universitario, como son la Sociedad de Ciencias Aranzadi y el Instituto de Historia Social Valentín de Foronda, al objeto de impulsar la recuperación de la memoria histórica relacionada con la guerra civil española de 1936 y el franquismo. Como manifiestan en su prólogo "apostar por recuperar la memoria histórica nos compromete a volver la mirada hacia los acontecimientos históricos ocurridos durante la Guerra Civil y el franquismo, y hacer un ejercicio de reconocimiento público y rehabilitación moral de las personas que fueron víctimas de las graves violaciones de Derechos Humanos cometidas entre los años 1936 y 1975. El olvido y la impunidad no son solamente fuente de dolor para las víctimas, son heridas abiertas que lesionan la democracia". En la consecución de estos objetivos, es decir rescatar del olvido y dignificar a las víctimas de la guerra civil y la posterior dictadura, han elaborado una página web, donde van actualizando las diferentes iniciativas promovidas por esta institución con el fin de impulsar y difundir la memoria histórica entre la sociedad vasca ${ }^{16}$. De entre ellas, vamos a destacar en las siguientes páginas las que consideramos tienen un valor didáctico para la enseñanza-aprendizaje de las Ciencias Sociales en general, y de la Historia en particular.

Esta página, por una parte contiene una sección dedicada a las personas "desaparecidas" y aporta un censo-índice nominal de las personas que han sido denunciadas como muertas, fusiladas o desaparecidas en el País Vasco por mor de

16 http://www.jusap.ejgv.euskadi.net/r47-contmh2/es/contenidos/informacion/oroimen historikoa/ es $\mathrm{mh} /$ presentacion.html 
la violencia y la represión ejercidas por las autoridades sublevadas y sus acólitos, y por el posterior régimen dictatorial que impusieron ${ }^{17}$. Su intención es conceder reconocimiento público y rescatar del anonimato a aquellas personas que "lucharon en defensa de la libertad y los valores democráticos". Más importante desde el punto de vista de la didáctica de la historia resulta la descripción del lugar, la fecha y las causas del fallecimiento de estas personas, pues a través de la indagación nos permiten recrear y aproximarnos al escenario de la guerra civil desde sus protagonistas. Así, a través de las causas y el lugar de los fallecimientos podemos ir localizando los diferentes frentes de batalla que asolaron el territorio vasco y su evolución en el tiempo; además, nos permite identificar otros lugares asociados a los rituales de muerte, pero que distan de los espacios de confrontación armada directa y están más ligados a prácticas represivas o de intimidación, como puedan ser prisiones, centros de detención, lugares de fusilamiento o poblaciones bombardeadas ${ }^{18}$.

Esta fuente nos permite desarrollar diferentes actividades de análisis e interpretación que darán lugar a la construcción del conocimiento sobre conceptos como detenciones ilegales, represión y vulneración de derechos, guerra y enfrentamiento armado, población civil, geografía del conflicto -constitución de frentes de batalla y relación con la orografía y la composición sociopolítica y económica del territorio-, etc. y su materialización en el País Vasco a través de la asimilación de acontecimientos históricos concretos (frente de Villarreal, batalla sobre Bilbao -monte Artxanda, Sollube- fusilamientos de Azáceta, bombardeo de Gernika). Para ello deberán recurrir a otras fuentes de información -bibliografía, Web grafía, hemerográficas, memoria y oralidad...-que complementen sus primeras indagaciones. A modo de ejemplo, si analizamos las muertes ocurridas en la localidad de Villarreal, podremos determinar que la mayoría de ellas están ligadas a la estabilización del frente como consecuencia del fracaso de la ofensiva emprendida por el Ejército de Euzkadi dirigida a liberar Vitoria. Además podemos situarlas cronológicamente entre finales de noviembre de 1936 y febrero de 1937, esta última fecha sería la del inicio de la campaña de Franco para ocupar Vizcaya.

Este procedimiento de análisis e interpretación de la información que nos ofrece el apartado de las personas desaparecidas, sería recomendable trabajarlo a través de diferentes programas informáticos destinados al tratamiento de bases de datos, que facilitarán enormemente la extracción de conclusiones. Atendiendo a criterios de uso, utilidad y conocimiento entre los discentes, recomendamos su vuelco sobre un programa Microsoft Office Excel y a continuación poner en relación las diferentes variables mediante el empleo de filtros (lugar de muerte, fecha, causa...).

17 El término de personas "desaparecidas" puede resultar eufemístico, pero oficialmente así fueron sentenciadas por carecer de certificado de defunción y cuerpo probatorio del fallecimiento.

18 Para profundizar en las prácticas represivas desarrolladas en la provincia de Álava por el bando rebelde durante la guerra civil se recomienda J. GÓMEZ CALVO: Matar, purgar, sanar. La represión franquista en Álava. Tecnos, Madrid: 2014. 
Seguidamente y en estrecha relación al apartado de personas desaparecidas, tendríamos un apartado relacionado con la Historia Oral. En él se recogen los relatos de vida y los recuerdos de los testigos directos y de segunda generación relacionados con la guerra civil y el franquismo. En estas cortas grabaciones en formato de video y que duran de unos 5 a 10 minutos se pone especial atención en los recuerdos de las prácticas represivas más conocidas llevadas a cabo en este periodo por el ejército franquista (bombardeo de Otxandiano en julio de 1936, de Bilbao en sucesivas ocasiones; experiencias de mujeres condenadas a muerte y encarceladas en la prisión de Saturrarán; fusilamientos a la par que los franquistas avanzaban en la ocupación del País Vasco -Donostia, Arrasate, Eibar...-; el encarcelamiento, los famosos paseos y la represión ejercida en la retaguardia alavesa). No obstante, este material audiovisual también resulta útil para internarse en el mundo de las mentalidades que azotaron esta etapa convulsa de nuestra historia reciente y reparar en las causas y en las motivaciones que precipitaron la confrontación armada y las consecuencias que todo ello acarreó sobre la población. De forma trasversal los aspectos de la vida cotidiana también pueden ser estudiados. Estos testimonios ayudarán al alumno en la comprensión e interpretación de los acontecimientos históricos asociados a la guerra civil y el franquismo y su cara más cruenta: la confrontación armada, la violencia y la represión, desde un punto de vista cercano y personal -con nombre y apellidos-, alejándonos de una visión aséptica que nada favorece la empatía y la motivación.

Por último y fruto de las investigaciones dirigidas desde la arqueología del conflicto y la arqueología forense, tendríamos la confección del mapa de las fosas presentes en el territorio vasco y provincias limítrofes ${ }^{19}$. Así, desde 2003 el Gobierno Vasco y la Sociedad de Ciencias Aranzadi han ido elaborando un análisis completo sobre las personas fusiladas y desaparecidas durante la guerra civil en el País Vasco, al objeto de recabar información sobre la posible ubicación de fosas comunes donde pudieran encontrarse enterrados sus restos. Este mapa de fosas es importante porque se inserta dentro de los parámetros de la arqueología pública y social o con vocación social, pues requiere de la participación y colaboración ciudadana y de las Asociaciones por la Recuperación de la Memoria Histórica y de historiadores contemporáneos y sus investigaciones basadas en fuentes documentales y orales para la localización de los posibles emplazamientos de las fosas y su activación patrimonial. Así, el conocimiento extraído de estos yacimientos revierte nuevamente en la sociedad.

Estos estudios están guiando las prospecciones y excavaciones arqueológicas a desarrollar en el presente y en el futuro, por lo que el mapa de las fosas es provisional, está en constante reelaboración y se va ampliando a medida que las

19 Para completar este mapa con informes relativos a exhumación de fosas de enterramiento de la guerra civil en otras comunidades autónomas limítrofes al País Vasco puede consultarse http://www. sc.ehu.es/scrwwwsr/Medicina-Legal/ 
nuevas investigaciones y exhumaciones arrojan mayores datos y conocimiento. En palabras de Hernández Cardona, la presencia de esta clase de enterramientos se da en contextos de combate donde se requieren sepulturas rápidas, porque el fragor de la batalla así lo recomienda. A ello debemos añadir los casos de sepelio de víctimas de la represión, que eran enterradas en lugares apartados al objeto de dificultar su investigación y la recuperación de sus cuerpos, y de este modo, no convertirse en un lugar de memoria para los represaliados que podría adquirir la categoría de símbolo capaz de aglutinar la identidad que se pretendía combatir ${ }^{20}$. Teniendo esto presente, esta aplicación nos permite vislumbrar los diferentes grados y naturaleza que adquiere la represión en los contextos bélicos, pues unos casos obedecen a confrontaciones armadas derivadas de los frentes de batalla, pero en otros casos son fruto de represalias originadas en un contexto de represión de retaguardia, a veces institucionalizada y previamente meditada, y otras debido a acciones incontroladas de exaltación política o de diversa índole (envidias, disputas familiares, rencillas personales...).

Este apartado del mapa de las fosas contiene diferente información. Primeramente sobre un mapa de la Comunidad Autónoma Vasca y empleando la aplicación cartográfica Google Maps sitúa cada una de las fosas de la Guerra Civil y la represión franquista de las que se tiene conocimiento. Está información visual un tanto caótica -por el número de fosas existentes- se recoge de forma ordenada en un despegable denominado "LOCALIZACIÓN", un fichero exhaustivo que divide las fosas en función de la provincia y término municipal en que se ubican.

Una vez seleccionada la fosa que queramos analizar, accederemos a una ficha informativa sobre los hallazgos realizados en las excavaciones arqueológicas de cada yacimiento y que tendrá los siguientes campos: localización; término municipal; territorio; coordenadas cartesianas UTM para su geolocalización; características de la fosa haciendo referencia al relieve y paisaje de su emplazamiento; informe preliminar donde prevalece la contextualización histórica y personal de las personas asesinadas; informe de los resultados de la exhumación - análisis de estructuras y de la tipología de los restos materiales, identificación de los cadáveres, etc...- e información iconográfica (fotografías, ortofotos...). A modo de ejemplo vamos a exponer en las siguientes líneas las fichas elaboradas para dos fosas comunes descubiertas recientemente entre 2010 y 2013. Cada una de ellas responde a una tipología diferente. La primera corresponde a una fosa vinculada directamente al frente de batalla de Villarreal; en cambio, la segunda está en relación con las labores represivas llevadas a cabo en la retaguardia.

La primera fosa que visitamos a través de esta TIC se encuentra en el pueblo de Etxaguen, perteneciente al término municipal de Zigoitia. Se halla en una parcela junto a la iglesia, pero carecemos de coordenadas para su geolocalización.

20 M. TORRUELLA y F.X. HERNÁNDEZ CARDONA: Didáctica de la Guerra Civil española..., ob. cit. p. 77 . 
El informe preliminar se basa en gran medida en los testimonios recogidos entre los vecinos de la zona y tras resultar positivo, ya que los ancianos del lugar tenían constancia de la existencia de una fosa común junto a la iglesia, se inició el plan de prospección. Una vez realizada ésta y confirmar los primeros hallazgos de cadáveres, se continuó con la excavación arqueológica. Fruto de esta labor, han aparecido al menos 12 cuerpos de personas desaparecidas que corresponden a hombres jóvenes, de unos 20 años, que fueron enterrados juntos y boca abajo. Entre los restos materiales se han encontrado objetos como mecheros, botones y lapiceros, pero la memoria arqueológica ha día de hoy está por concluir y publicar, por lo que no podemos dar más detalle. Se intuye que estos cuerpos pertenecieron a milicianos del batallón comunista Facundo Pérez Agua, que estuvo destinado en estas inmediaciones durante la ofensiva republicana.

Por lo que respecta a la fosa ubicada en Pobes, conocida por El hoyo de los muertos, ésta se encuentra en las inmediaciones del puerto de la Tejera, en la cuneta derecha de la segunda curva de la carretera que une los pueblos de Paul y Salinas de Añana, debajo de un promontorio lleno de maleza (Coordenadas UTM X 503,144; Y 4.733.177; Z 720). El informe preliminar, tras recoger el testimonio de tres vecinos de Salinas de Añana que aseguraron conocer la existencia de tres personas allí liquidadas y de no haber sido removido el emplazamiento, fue positivo. Se sospechaba de la identidad de estas personas y según los relatos de los lugareños correspondían a Mónica Barrón del Val y a Florentino García Valencia, matrimonio de labradores vecinos del pueblo cercano de Villanueva de Soportillo (Burgos) y de 47 y 46 años de edad respectivamente; el tercer fusilado sería Primitivo Fernández de Labastida Urruchi, labrador natural de Santa Gadea (Burgos) y de 35 años de edad. Éstos fueron requeridos por voluntarios carlistas del requeté en septiembre de 1936 al objeto de tomarles declaración en Vitoria por su vinculación con la causa republicana y simpatía por las fuerzas de izquierda. Nunca más se sabría de su existencia y viene a ser un ejemplo más de lo que Julián Casanova Ilamó "terror caliente"21. Tras estas evidencias se procedió a la excavación del yacimiento, y una vez analizadas las osamentas, se confirmó la posible compatibilidad de las identidades. Los cadáveres presentaban un orificio en la cabeza. Aparte de los cuerpos entre las trazas materiales también apareció una peineta.

Los hallazgos materiales rescatados de estas fosas pueden ser tratados didácticamente a través de procesos inductivos o hipotético- deductivos con la intención de contextualizarlos históricamente. Primeramente es conveniente que el alumno repare en los retos materiales hallados en estos yacimientos (cuerpos de hombres o de mujeres, botones, mecheros, lápices, peinetas...), en la información que puede proveer cada uno de ellos y el porqué de su existencia. Posteriormente podemos

21 J. CASANOVA RUIZ: Rebelión y revolución. En S. JULIÁ DÍAZ (coord.): Víctimas de la Guerra Civil. Temas de Hoy, Madrid: 1999, pp. 55-177. 
conducir el proceso de aprendizaje a través del planteamiento de hipótesis o la formulación de preguntas sobre los objetos encontrados y la relación de las distintas trazas materiales, que el alumno tendrá que tratar de resolver. Cuestiones como las siguientes pueden guiar este proceso: ¿Quién eran esas personas? ¿Por qué estaban allí? ¿Cuales creéis que fueron las causas de fallecimiento de estas personas? Fíjate en el cadáver y los posibles orificios ¿Por qué eran tan jóvenes? ¿En qué sustentas tu deducción? Fijándonos en la disposición de los cadáveres ¿Por qué los enterraron boca abajo? ¿Por qué en una de las fosas no se encuentran mujeres y en la otra sí? ¿Qué objetos se encuentran? ¿Por qué estaban allí? ¿Cuál era su uso o para qué servían? A raíz de los objetos materiales hallados en la fosa, ¿cómo crees que era la vida de estas personas?, ¿Qué ropas llevaban? ¿Qué importancia tiene el lápiz hallado en una de estas fosas?, ¿Qué importancia tiene el hallazgo de los encendedores? ¿Qué importancia tiene el hallazgo de la peineta? ¿Qué nos indican? ¿Crees que pasaron por un centro de detención?, etc ${ }^{22}$.

\section{Conclusiones}

Lo aquí expuesto no deja de ser un esbozo de la potencialidad didáctica que se puede desarrollar alrededor del patrimonio arqueológico de la guerra civil a través del uso de un recurso interactivo que nos proporcionan las TIC. El empleo del Mapa de Fosas de Euskadi resulta altamente positivo ya que encamina el proceso de enseñanza-aprendizaje por tres vías distintas que llegan a confluir. Primeramente nos ofrece el mapa de las fosas, estructurando la acción represiva sobre el mapa georeferenciable y complementándolo ocasionalmente con fotoplanos; en segundo lugar un análisis objetual de los diferentes materiales arqueológicos hallados en los yacimientos que nos acercara a la vida cotidiana de aquellas personas y a las causas de su muerte; por último, contextualiza las fosas con el recurso de la historia oral, a través de los testimonios y de la memoria bien directa bien indirecta de los familiares y conocidos de las personas represaliadas por el régimen franquista.

No obstante, esta herramienta didáctica puede ser complementada con la información que nos aportan las Memorias Arqueológicas de cada yacimiento. Éstas proporcionan una información más detallada y con un mayor rigor científico, pero por su grado de complejidad su empleo en el aprendizaje de la Historia debe ser calibrado adecuadamente y sometido a transposición didáctica. Respecto a la información que nos aporta esta TIC sobre las fosas del País Vasco, hay que resaltar que en algunos casos es incompleta, ya que se está a la espera de que la exhumación sea realizada o que el informe pertinente sea adjuntado; por otra

22 Para una metodología de análisis de los restos objetuales provenientes de las excavaciones arqueológicas se recomienda J. SANTACANA,: "Analizemos objetos para la escuela y el museo". Didàctica del patrimoni cultural [en línea], 2010. <didcticadelpatrimonicultural.blogspot.com.es>. [Consulta: enero 2013] 
parte, la información proveniente de los testimonios orales no es lo adecuada que podría preverse, pues no ha pasado el filtro científico que todo relato necesita, pues aparte de la subjetividad, la memoria en ocasiones juega malas pasadas (reelaboración en función de la evolución personal, peligro de presentismo, falta de concreción cronológica... ${ }^{23}$. No obstante, estas deficiencias que pudieran parecer un serio revés en el proceso de enseñanza-aprendizaje, se transforman en una ventaja. La ausencia de suficiente información o en su caso de información errónea, nos obligará a iniciar un proceso de investigación paralelo que complete de forma satisfactoria las lagunas que el mapa de fosas y los relatos han dejado, potenciando en el discente la reflexión crítica sobre la veracidad de los medios de comunicación y profundizando en los procedimientos referidos al tratamiento de la información a través del contraste. Consecuentemente, en este ejercicio de indagación el alumno tendrá que recurrir a diferentes fuentes de información, tanto históricas como de actualidad, y contrastarlas para perfeccionar su conocimiento, favoreciendo de este modo un pensamiento crítico.

Este recurso TIC tiene otra virtud, pues deja la puerta abierta a propuestas presenciales de educación patrimonial basadas en espacios museográficos y de memoria histórica. Así, su labor divulgativa y didáctica ha sido complementada por varios proyectos museográficos como el patrocinado por la Sociedad de Ciencias Aranzadi titulado "Exhumando fosas, recuperando dignidades" que han dado a conocer al público en general los hallazgos materiales y los conocimientos adquiridos en las diferentes campañas arqueológicas llevadas a cabo, unidos a documentación y relatos de vida de los testigos que ayuden en la interpretación y comprensión de los acontecimientos históricos asociados a la guerra civil y su cara más cruenta -la confrontación armada, la violencia y la represión-. Su objetivo es formar "un espacio para aprender, para investigar, para generar conocimiento, para emocionarse y para pensar", a través de la interacción entre el visitante y el objeto ${ }^{24}$.

El uso de esta TIC en la enseñanza-aprendizaje de la guerra civil también puede complementarse con trabajo de campo y salidas escolares bien planificadas para visitar el yacimiento que más cercano resulte al centro escolar y que esté habilitado para actividades didácticas. Estas salidas programadas también permiten acercarnos a otros espacios de la arqueología del conflicto y de memoria histórica como pueden ser las trincheras o los monumentos commemorativos ${ }^{25}$. De este modo, las fosas y el patrimonio cultural y arqueológico de la guerra civil permiten

23 P. THOMPSON: La voz del pasado. Historia oral. Ediciones Alfons el Magnánim, Valencia: 1988. 24 J. SANTACANA y J. MARTÍN PIÑOL (coord.): Manual de museografía interactiva. Trea, Gijón: 2010; F.X. HERNÀNDEZ CARDONA y M. ROJO ARIZA (coord.): Museografía didáctica e interpretación de espacios arqueológicos. Trea, Gijón: 2012; J. SANTACANA y F.X. HERNÀNDEZ CARDONA: Museos de historia. Entre la taxidermia y el nomadismo. Trea, Gijón: 2011, p. 253.

25 Para una reflexión sobre el encauzamiento de las salidas escolares se recomienda P. BENEJAN: "Los objetivos de las salidas". Íber, Didáctica de las Ciencias Sociales, Geografía e Historia, 36 (2003). 
un viaje en el espacio y en el tiempo propicio para la didáctica de la historia. Una aproximación vivencial al yacimiento, a las líneas del frente o a los memoriales ${ }^{26}$ supone una actividad extraordinariamente positiva de cara a la observación y a la interpretación que nos permitirá profundizar en algún aspecto de la realidad que haya sido planteado previamente en el aula. Esta práctica formaría parte del modelo indagatorio de verificación de hipótesis propuesto por Palacios, con sus cuatro fases clásicas: preparación en el aula, realización en el medio, explotación en el aula y aplicación de lo aprendido ${ }^{27}$.

Como corolario y trayendo a estas páginas las palabras de Andrés Zarankin planteadas en su estudio de la represión de la dictadura argentina, uno de los objetivos de la arqueología del conflicto es "contribuir a la construcción de una memoria material. Es decir transformarla en algo físico, para así poder ser percibida de maneras diferentes a la palabra (oral o escrita). Una memoria que pueda ser tocada, olida, experimentada. (...) una forma de recuperar la memoria, y a través de ella, contraponerse a la historia que nos fue transmitida" ${ }^{28}$. Teniendo esto presente, las implicaciones didácticas de esta disciplina arqueológica resultan más que interesantes.

\section{Bibliografía}

P. ALONSO GONZÁLEZ: "Reflexiones en torno a una Arqueología de la Guerra Civil: el caso de Laciana (León, España)". Munibe (Antropología-Arkeología), 59 (2008), pp. 291-312.

J.A. ÁLVAREZ OSÉS et al.: La guerra que aprendieron los españoles. República y guerra civil en los textos de bachillerato (1938-1983). Libros de la Catarata, Madrid: 2000, p. 76.

A. AZCARATE y I. GARCÍA: "La ciudad, documento histórico: reflexiones sobre la práctica de la arqueología urbana en la comunidad Autónoma del País Vasco". KOBIE (serie paleoantropología), 23 (1996), pp. 141-161.

\footnotetext{
26 Reflejo del valor didáctico del patrimonio monumentístico es la iniciativa germinada en los años 90 del pasado siglo en torno el programa "La escuela adopta un monumento". Para profundizar en este aspecto se recomienda A. BARDAVIO, C. GATELL ARIMONT, P. GONZÁLEZ MARCÉN, M. ÁNGEL JARA, R. SOLSONA FONTOVA: "Teoria i pràctica de l'adopció escolar de monuments. L'experiència de la Universitat Autònoma de Barcelona i el Camp d'Aprenentatge de la Noguera". Treballs d'Arqueologia, 15 (2009), pp.103-121.

27 D. PALACIOS: "La aplicación del método indagatorio a la enseñanza de la Geografía a través del trabajo de campo", Actas de las Primeras jornadas de Didáctica de la Geografía. AGE, Madrid: 1988.

28 P. P. A. FUNARI y A. ZARANKIN (eds.): Arqueología de la represión y la resistencia en América Latina (1960-1980). Universidad Nacional de Catamarca, Córdoba: 2006.
} 
A. BARDAVIO, C. GATELL ARIMONT, P. GONZÁLEZ MARCÉN, M. ÁNGEL JARA, R. SOLSONA FONTOVA: "Teoria i pràctica de I'adopció escolar de monuments. L'experiència de la Universitat Autònoma de Barcelona i el Camp d'Aprenentatge de la Noguera". Treballs d'Arqueologia, 15 (2009), pp.103-121.

P. BENEJAN: "Los objetivos de las salidas". Íber, Didáctica de las Ciencias Sociales, Geografía e Historia, 36 (2003).

J.A. BLANCO RODRÍGUEZ: "La historiografía de la guerra civil española". Hispano Nova, 7 (2007).

V. BUCHELI y G. LUCAS: Archaeologies of the Contemporary Past. Routledge, Londres:2001.

J. CASANOVA RUIZ: Rebelión y revolución. En S. JULIÁ DÍAZ (coord.): Víctimas de la Guerra Civil. Temas de Hoy, Madrid: 1999, pp. 55-177.

F. FERRÁNDIZ MARTíN: "Exhumaciones y políticas de la memoria en la España contemporánea". Hispano Nova, 7 (2007).

- P. P. A. FUNARI y A. ZARANKIN (eds.): Arqueología de la represión y la resistencia en América Latina (1960-1980). Universidad Nacional de Catamarca, Córdoba: 2006.

A.L. GARCÍA RUIZ (coord.): Didáctica de las Ciencias Sociales, Geografía e Historia en la Enseñanza Secundaria. Grupo Editorial Universitario, Granada: 1997, pp. 239-242.

J. GÓMEZ CALVO: Matar, purgar, sanar. La represión franquista en Álava. Tecnos, Madrid: 2014.

A. GONZÁlEZ RUIBAL: "Arqueología de la Guerra Civil Española". Complutum, 19 (2008), pp.11-20.

M. GRAS: "Modelos teóricos en el aprendizaje II" en A. AGUIRRE y J.M ÁLVAREZ: "Psicología de la educación". PPU, Barcelona: 1987, pp. 135-162.

F.X. HERNÁNDEZ CARDONA y X. RUBIO: "Arqueología, conflicto y didáctica. El Born, siglo XVIII". Íber, Didáctica de las Ciencias Sociales, Geografía e Historia, 73 (2013), pp. 35-42.

F.X. HERNÀNDEZ CARDONA y M. ROJO ARIZA (coord.): Museografía didáctica e interpretación de espacios arqueológicos. Trea, Gijón: 2012.

J. MONTERO GUTIÉRREZ: "La visibilidad arqueológica de un conflicto inconcluso: la exhumación de fosas comunes de la Guerra Civil española a debate". Munibe (Antropología-Arkeología), 60 (2009), pp. 289-308.

A.T. MYERS: "Between Memory and Materiality: an Archaeological Approach to Studying the Nazi Concentration Camps". Journal of Conflict Archaeology, 4 (1-2) (2008), pp. 231-245.

D. PALACIOS: "La aplicación del método indagatorio a la enseñanza de la Geografía a través del trabajo de campo", Actas de las Primeras jornadas de Didáctica de la Geografía. AGE, Madrid: 1988. 
J. PRICE: "Orphan Heritage: issues in Managing the Heritage of the Great War in Northern France and Belgium". Journal of Conflict Archaeology, 1 (1) (2005), pp. 181-196.

J. SANTACANA y F.X. HERNÀNDEZ CARDONA: Museos de historia. Entre la taxidermia y el nomadismo. Trea, Gijón: 2011, p. 253.

J. SANTACANA,: "Analizemos objetos para la escuela y el museo". Didàctica del patrimoni cultural [en línea], 2010. <didcticadelpatrimonicultural.blogspot. com.es>. [Consulta: enero 2013].

J. SANTACANA y J. MARTÍN PIÑOL (coord.): Manual de museografía interactiva. Trea, Gijón: 2010.

N.J. SAUNDERS: "Excavating Memories: Archaeology and the Great War, 19142001". Antiquity, 76 (291) (2002), pp. 101-108.

J. SCHOFIELD, W. G. JOHNSON y C. M. BECH (eds.): Matériel Culture. The Archaeology of twentieth century conflict. Routledge, Londres: 2002.

P. THOMPSON: La voz del pasado. Historia oral. Ediciones Alfons el Magnánim, Valencia: 1988.

M. TORRUELLA y F.X. HERNÁNDEZ CARDONA: Didáctica de la Guerra Civil española. Graó, Barcelona: 2013

R. VALLS MONTES: Historia y memoria escolar. Segunda República, Guerra Civil y dictadura franquista en las aulas. Publicacions de la Universitat de Valencia, Valencia: 2009, p. 113.

O. VERGARA: "Arqueología Industrial. Un comentario bibliográfico tras medio siglo de historiografía". AnMurcia, 25-26 (2009-2010), pp. 275-300.

A. ZABALA y L. ARNAU: 11 ideas clave. Cómo aprender y enseñar competencias. Graó, Barcelona: 2007, pp. 53-63. 
